\title{
A Postdoc's Guide to Being a Postdoc
}

Stefanie B. Marquez

University of Florida College of Medicine, Division of Hematology/Oncology, 2033 Mowry Road Cancer

Genetics Research Complex Room 290 Gainesville, FL 32610, USA

Email: stefanie.marquez@ufl.edu

\begin{abstract}
If you have recently accepted a postdoctoral position and have begun working as a postdoc, or are planning to pursue a second postdoc, there are many opportunities to improve your skills both within and outside of academics and your specific field of study. The suggestions offered in this paper are not all-inclusive by any means, and are meant to serve as guidelines to show postdocs what they can do, not necessarily what they should do. This is my perspective as a third-year postdoctoral researcher in the medical sciences.
\end{abstract}

Keywords: academia, career development, networking, postdoctoral mentoring

\section{Define Yourself}

Postdocs are a unique species and are often categorized as a hybrid cross between a graduate student and a faculty member. In fact, in my own experience, many laypersons have never even heard the term "postdoc." While I sometimes find myself defining a postdoctoral position as something in between a student and a professor, this classification is ultimately, for most postdocs, incorrect. Most of us in scientific fields are aware of what has been deemed the "traditional," and albeit the path considered "most acceptable." It is expected that undergraduates who do well with a science major move on to graduate school (or medical school), and then to a postdoctoral fellowship, and finally, to a full-fledged faculty position. Historically, scientists who follow this path have been, for the most part, regarded as "successful" by their peers. This narrow definition of success leaves little room for scientists who don't want to work in academia or perhaps want to work in an academic setting other than a research laboratory. Since so many career opportunities exist for scientists with PhDs, different postdocs may provide distinct descriptions of their training and where they hope it leads them. In my opinion, it's important for all of us to really think about the roles we play as postdocs and what we hope to achieve. Many of the suggestions in this article can be helpful to any postdoc regardless of whether he or she ultimately pursues an academic position.

\section{Talk to your Mentor}

If you have just started a postdoc position, consider asking your PI to sit down with you to discuss what is expected of you during your time in his or her lab. Your PI should outline his or her expectations for you. Likewise, you should outline the expectations you have for yourself and for your mentor. The American Association of Medical Colleges (AAMC) has developed a compact for postdoctoral appointees and their mentors along with some guidelines, which may serve as a good starting point for your discussion. A conversation with your PI that defines your expectations can help prevent any misunderstandings that might arise. Ideally, this conversation would occur before a position is accepted and before a contract is signed. Although the following questions may seem elementary, not all PIs and prospective postdocs discuss these topics during the interview process. 
Some common questions or concerns you may want to discuss are as follows:

- Will I have any teaching responsibilities? If I want to teach, will I have the opportunity to do so?

- What is the salary, and what is the yearly increase (if any)?

- How many hours am I expected to work each week?

- What is your vacation policy?

- How many first-author publications am I expected to submit each year?

- How involved are you with your lab's research team, and how often are you available to discuss any problems I may encounter?

- Will I have the chance to mentor undergraduate or graduate students?

- Do you encourage us to attend scientific conferences, and who is responsible for the cost to attend? How often will I be able to (or be expected to) showcase my research?

- Will I have the chance to apply for my own funding?

- Can I help you review grants and manuscripts?

- What departmental activities can I participate in? (e.g. grand rounds, weekly or monthly lecture series, volunteering to help with poster sessions, etc.)

- What types of resources does our institution offer postdocs?

- Are there annual reviews to assess my progress? What will happen if I don't meet all of your expectations?

These are important questions that many postdocs and prospective postdocs fail to ask, or don't realize they should ask. For most of us, a postdoc position is not merely a temporary job until we find something that pays better. It's actually an important training period necessary for us to be successful in our careers. While graduate students in the life sciences typically spend 4-5 years or more working on their projects and publishing papers, postdocs usually operate within a much shorter timeframe. As postdocs, we're expected to develop research projects with our PIs, demonstrate the ability to think and function independently, and complete one or more projects in anywhere from 1-3 years. Considering this shorter timeframe, it's essential to maximize productivity. Of course, what it means to be productive can depend on the type of career you choose. On the one hand, if you plan to teach exclusively, it may not be necessary to publish that elusive Cell or Nature paper; on the other hand, it may benefit you to teach at a local community college. Given the limited time we have, it's imperative to discover your niche early in your postdoc career, to be aware of what you're expected to contribute to your lab, and to figure out what you hope to gain from your postdoc experience. Finally, the postdoctoral training period should provide the necessary framework to help you choose a career when your training ends.

\section{Develop an IDP}

Chances are, if you can get your PI to discuss expectations, you can also get him or her to help you create an IDP, or individual development plan. There are many resources you can use to create and maintain an IDP, such as Science Careers My IDP Portal. You're already swamped working on several projects, so why spend the time creating an IDP? The 2005 Sigma Xi survey of 7600 postdocs indicated that postdocs who developed some variation of a career plan with their advisors reported a higher level of satisfaction, more publications, and fewer adverse interactions with their mentors (Davis, 2005). According to Jonathan Gitlin (2008), the Sigma Xi survey suggested that "implementing an IDP had the same effect on a postdoc's personal well- being as a $\$ 20,000$ pay raise." Since the creation and implementation of an IDP often means more publications, this is another convincing reason why your PI should help you devise and maintain an IDP: It's a win-win situation for both of you. 
The first step is a self-assessment where you consider your skills, weaknesses and interests. You may want to ask others to gauge what your strengths and weaknesses are, such as a friend, a colleague in the lab or even a family member. Let them know that it's okay for them to be honest, even if they're critical. Hearing what our perceived strengths and weaknesses are from others we work with is important constructive criticism that can help us improve. You might discover a weakness that you hadn't given much thought to, and therefore never addressed, or you might become aware of a strength you didn't even know you had.

The second step requires you to explore different career opportunities. Obviously, academia is not the right career choice for all of us. Many graduate students and postdocs often consider the traditional conundrum of academia versus industry, without giving much thought to the many diverse careers within these two realms. The formulation of an IDP can help us discover the options we have as PhDs, and you can then see which options are a good match for your particular interests and skill set.

Third, you set goals as to how you'll work towards your career (s) of choice. You make a plan for how you'll accomplish each of your goals, how you will obtain the proper experience and how you will hone your skills.

Lastly, you implement your plan and enlist the help of different mentors in order to achieve your objectives. While your PI may be a great mentor, he doesn't know everything. If your PI is a professor, he or she may know very little about what it's like to work as anything but a professor or lab director. This doesn't help you much if you've already decided to pursue a nonacademic track. Networking and searching for other role models will give you alternative perspectives that can help you decide your own career path and determine whether you're headed in the right direction.
An IDP created at the start of a science career can help you plan your career trajectory. You can continue updating your IDP as you become more experienced, as well as make changes as necessary. It's imperative that you return to it every so often to assess whether or not you have achieved any of your stated goals, whether you have improved your skills in a particular area, and if you're making adequate progress towards your career of choice. In fact, the Science Careers IDP portal sends occasional email reminders so that we don't forget to return to our IDPs and update them.

Pam Denicolo (The Guardian 2014), a professor at the University of Surrey, recommends the Vitae Researcher Development Framework, which allows you to identify how your specific skills and experiences can enhance your success in various types of careers. This site also features a blog that is dedicated to a discussion of the pros and cons of academic life (not just science!) and a section that highlights career development advice from professionals. The point is, there are many tools out there, both online and within your academic department that you can use to enrich your technical and non-science skills during your postdoc.

\section{Know Yourself}

An important aspect of a postdoc is figuring out your "post-postdoc." What do I want to do with my life after my current postdoc is finished? Obviously, there are myriad choices including, but not limited to, completion of a second postdoc, additional formal education (e.g. MD, $J D, M B A$, etc.), a non-tenure or tenure-track academic position, a position at a teachingcentered college or university, administrative or executive leadership in academia or industry, and finally, a research position in academia or industry. While it may seem odd to some that, as postdocs, we don't know exactly what we want to do with our lives at this point, I think it has become an all too common phenomenon in recent years. This is not surprising considering that many science postdocs who want an 
academic position are unable to obtain one, which forces them to make another choice. Sometimes, though, we may discover along the way that maybe the "holy grail" tenure-track academic position is not what we ultimately want for ourselves. Many factors contribute to this decision, including ability to obtain funding, family issues, and finances.

Fortunately, there are many career "alternatives" to academia. Some have even argued that the use of the term "alternative" to describe any career other than an academic one is misleading and pretentious since it assumes that academia is the "default" pathway and desired career for most, if not all, science PhDs (Stemwedel 2013). Thankfully, it seems many scientists are distancing themselves from the "traditional" view of success, and have embraced "alternative" careers as equally successful. The burgeoning of such "alternative" careers in recent years has changed the landscape of science. In a discipline where it was expected that a science PhD seek and accept an academic appointment, we're now seeing scientists in other positions, such as regulatory scientist, medical writer, or policymaker, to name a few. Since the number of postdoctoral scientists who would like to pursue a career in academia far exceeds the number of available spots, many of us are choosing other types of careers, but how do we know what to choose? Fortunately for us, many scientists, postdocs and professors have taken to blogs to write about the current situation that faces prospective academics.

\section{Know your Options}

A resource for postdocs who hope to begin a career in academia is the Howard Hughes Medical Institute/Burroughs Wellcome Fundsponsored guide entitled, "Making the Right Moves: A Practical Guide to Scientific Management for Postdocs and New Faculty," an all-inclusive guidebook to being a PI. An academic career is not for everyone, but unfortunately, many graduate students and postdocs are not exposed to other types of careers early in the course of their training, and therefore, often don't know how or when to step off of the academic career path (Shea 2013). Free web content such as Jo Van Every and Julie Clarenbach's Escape the Ivory Tower features a free e-class called "Myths and Mismatches" that may help struggling and doubtful academics figure out if their current career is suitable for them.

The Wellcome Trust's "Postdoc Plan B," and Dr. Karen Kelsky's The Professor is In blog are just two resources where readers can gain a sense of current academic prospects. Dr. Kelsky, for example, features a blog that discusses the academic job market as well as topics such as "How to Get Grants," "Strategizing Your Success in Academia" and "'Yes, You Can-Women in Academia." Her blog is informative and gives multiple perspectives since she was a tenured professor and department head, but chose to leave academia. Her blog (free of charge), and the services she provides (for a fee of course) are examples in and of themselves of what a science PhD can do outside of the academic (and industry) realm. In fact, there are a number of online services that cater to postdocs and individuals in various stages of their careers. Although it is limited to UC Berkeley, the Beyond Academia conference has the goal of connecting graduate students and $\mathrm{PhDs}$ with innovative career and education services.

\section{Take Advantage}

Sometimes our mentors may not like the idea of us leaving the lab for a few hours to attend a workshop, and some PIs may, at times, neglect their responsibility to train us. Let's face it. Some of us may be "stuck" with a self-centered PI who seems to care only about getting results and publishing papers, and not so much about "you". While most would agree that those things are extremely important both for your career and your Pl's, it's also essential to develop other aspects of your career outside of publications. This includes attending national conferences, 
socializing, networking, and attending events right in your own backyard.

If there are a large number of postdocs at your university or institution, there is likely some sort of "governing body" for postdocs, such as an office of postdoctoral affairs. For instance, here at the University of Florida, our office sponsors monthly career development workshops that are geared towards postdocs, but that may also be pertinent for graduate students and junior faculty. Topics range from mental health to CV and interview prep to grant writing. They're a great way to improve your non-science skills because whether you want to run your own lab or work in industry, success requires more than just doing good science. Other institutions such as the University of Pittsburgh provide postdocs in the health sciences with a career progress assessment and a mentoring team for trainees. MIT mandates performance reviews for postdocs, and requests that PIs and postdocs define the training goals for each new postdoc (Sive et al. 2013). Even if your institution doesn't have an office of postdoctoral affairs, there are still opportunities for career development. Postdoctraining.com , founded by a former postdoc and her husband, offers workshops to help postdocs with the job search, leadership skills and time management, among others. Although there is a fee to access most of what the site has to offer, there is a blog with tips and advice for postdocs that is free of charge.

The National Postdoctoral Association website features six core competencies (disciplinespecific conceptual knowledge, research skill development, communication skills, professionalism, leadership and management skills, and responsible conduct of research) as well as resources to improve in each of these areas. It is suggested that postdoctoral scholars reflect on these core competencies throughout the training period in order to measure their desired skill acquisition. Overall, the NPA offers great resources for postdocs. Some institutions may even provide postdocs with a complimentary affiliate membership in the NPA. If not, it's an organization worth joining.

Our office at UF also sponsors social hours where postdocs from all fields can socialize in an informal setting. Many postdocs, especially international postdocs, come to their university with no family or friends, or maybe with a spouse and a child. Social interactions and networking with peers is a crucial aspect of academic success for many postdocs (Stobbe et al. 2013) and is important not just for one's professional development but for personal development as well. If you're shy or nervous because you don't know anyone, many other postdocs probably are, too. Encourage your colleagues in the lab to go with you. Food and drinks aside, this is an excellent way to begin networking among postdocs within and outside your field of study. Socializing outside of the workplace can lead to new friendships and future collaborations. We're all postdocs now, but who knows where we'll be in five years. The old adage really is true: sometimes it's not what you know, but who you know.

\section{Shop Around and Get Involved}

No mentor is perfect, and nobody is an expert in every aspect of his or her chosen field. Therefore, it might be in your best interest to connect with other senior scientists or faculty members who can mentor you in ways that perhaps your PI cannot. If your PI is a good leader, he'll realize his shortcomings and encourage this practice, if not introduce you to some valuable people. Having more than just one mentor means that you'll be familiar (at the very least) with multiple disciplines, and generally, this will make you more appealing to future employers. You'll also be exposed to different mentoring styles which can be a major advantage as you formulate your own distinctive style. Mentors are also an excellent source for collaborations and for providing recommendation letters when you begin to search for your next position. 
A popular way to meet people is through social networking. Many university groups have private Facebook and Linkedln pages, where members can share recently published articles, initiate a lively discussion, advertise a pertinent event on campus, or even just ask a question. Besides postdoc societies and the like, there may be other groups at your institution that cater to a specific audience (e.g. women in science and engineering, postdoc parents, etc.) that may be relevant to you. Often, these organizations sponsor workshops and events that are designed for learning and networking to enhance your professional skills. Representatives of the NPA regularly post articles on Linkedln and allow for comments and discussions. If you don't have a LinkedIn profile, I suggest creating one. It allows you to showcase your skills and achievements and to connect with others who have similar interests or career goals. There are many other websites with similar purposes, such as Research Gate, LabRoots, Viadeo, and SciVal.

Your institution might also have a career resource center. Here at the University of Florida, postdocs can use the career resource center for CV development, to improve interview skills, and to attend the semiannual career showcase on campus. Typically, events such as the career showcase and even use of the career resource center have been reserved for students. However, as more universities continue to recognize the need to extend these resources to postdocs, it never hurts to inquire what your options are.

\section{Conclusion}

It's important to recognize the significant role postdocs play in research labs. Postdocs are frequently responsible for many of the major discoveries in science, and are thus valuable members of the research community, not cheap labor to be exploited. While it may be true that you are responsible for producing data, publishing papers and being productive, thus helping your PI to obtain more funding or a promotion, your $\mathrm{PI}$ also has a responsibility to train you. Despite any obligation or commitment on your Pl's behalf, ultimately, this is your postdoc. There is no handbook that describes how to be a $\mathrm{Pl}$, or how to pick a career. As postdocs, we've been able to develop essential skills that are transferable to a wide array of careers, not just to an academic appointment. It's in our best interest to define, and further develop these skills so that we're able to compete with the cream of the crop, for our chosen careers. Ten years ago, you'd be hardpressed to find more than a handful of universities with an office of postdoctoral affairs. As a consequence, many current mentors and Pls may not have had the opportunities that are present today to further develop their skills. We're only postdocs for a short time, and no matter what our career paths may be, we can't reclaim missed opportunities. I hope much of what I have written here will encourage postdocs to make the most of their experience.

\section{References}

Davis G. Doctors without orders. American Scientist 2005. 93 (3, supplement). http://postdoc.sigmaxi.org/results/

Denicolo P, Reeves J and Duke D. Leaving academia? How to sell yourself to new employers. The Guardian January 2014.

Gitlin J. Establishing career platforms for postdocs through individual development plans. Disease Models and Mechanisms. 2008 JulAug; 1(1): 15.

Shea A. For Graduate Programs, It's Time to Get Real. The Chronicle of Higher Education, February 25, 2013.

Sive $\mathrm{H}$, Canizares C, Zuber M. The status of MIT's postdoctoral researchers. MIT Faculty Newsletter Vol. XXVI No. 2 November/December 2013.

Stemwedel J. Careers (not just jobs) for PhDs outside the academy. Doing Good Science Blog, Scientific American, November 30, 2013. 
Stobbe M, Mishra T, Macintyre G. Breaking the ice and forging links: the importance of socializing in research. PLOS Computational Biology. Volume 9 Issue 11, November 2013.

http://myidp.sciencecareers.org/

http://www.oacd.health.pitt.edu/postdocprogre ss/

http://postdoctraining.com/

http://www.nationalpostdoc.org/

https://www.aamc.org/initiatives/research/post doccompact/ 